\title{
A study of the effect of family climate on social competence in adolescents
}

\author{
VARSHA GOEL* AND RITU GARG \\ Department of Home Science, Shri Ram Girls College, MUZAFFARNAGAR (U.P.) INDIA
}

\begin{abstract}
Present study was conducted to know the influence of family climate on social competence of an adolescent is of great importance. Family climate affects the social competence during a more crucial period in life, i.e. adolescence. Adolescence is often considered as a period of "storm and stress". Any negligence of the individual at this stage leads to serious problems in later life which is bad not only for the individual but also for all those who come in contact with him and for the society in which they live.Study was carried out on 100 adolescents (50 boys and 50 girls) from Agra city. The results show gender differences in perception of the family climate and social competence which proves that in Indian culture specially that of small cities.the parents still give differential treatment to their sons and daughters and the society has certain gender biases still prevailing.
\end{abstract}

KEY Words : Family climate, Social competence, Adolescents

View Point Article : Goel, Varsha and Garg, Ritu (2015). A study of the effect of family climate on social competence in adolescents. Internat. J. Home Sci. Extn. \& Comm. Manage., 2 (1): 49-57.

Article History : Received : 25.11.2014; Revised : 05.12.2014; Accepted : 19.12 .2014

* Author for correspondence: (Email : varshag79@ gmail.com) 